\title{
Large-scale nanopatterning of single proteins used as carriers of magnetic nanoparticles
}

\section{Ramsés V. Martínez, Javier Martínez, Marco Chiesa, Ricardo García}

Instituto de Microelectrónica de Madrid, CSIC, Isaac Newton 8, 28760 Tres Cantos, Madrid (Spain)

\section{mchiesa@imm.cnm.csic.es}

Accurate and reproducible patterning of proteins and functional nanoparticles is essential to exploit their properties in nano and microscale devices [1]. Electrostatic interactions, capillary forces, surface functionalization and nanolithography can be used in combination or independently to achieve the desired protein organization [2]. Here, we report a simple yet efficient method to deposit ferritin proteins with nanoscale accuracy over large areas. The selective deposition is driven by the electrostatic interactions existing between the proteins and nanoscale features. The efficiency of the deposition process can be controlled by changing the $\mathrm{pH}$ of the solution. By combining a top-down tip-based nanolithography [3] and bottom-up electrostatic interactions we have formed regular arrays of ferritin molecules with an accuracy that matches the protein size $(\sim 10 \mathrm{~nm})$. Magnetic force measurements confirm the magnetic activity of the deposited nanoparticles.

\section{References:}

[1] W. Cheng, T. Walter, D. Luo et al., Nature Nanotechnology 3 (2008) 682.

[2] R.V. Martinez, R. Garcia, E. Coronado et al., Adv. Mater. 19 (2007) 291.

[3] R.V. Martínez, J. Martínez, M. Chiesa et al., Adv. Mater. DOI: 10.1002/adma.200902568

\section{Figures:}

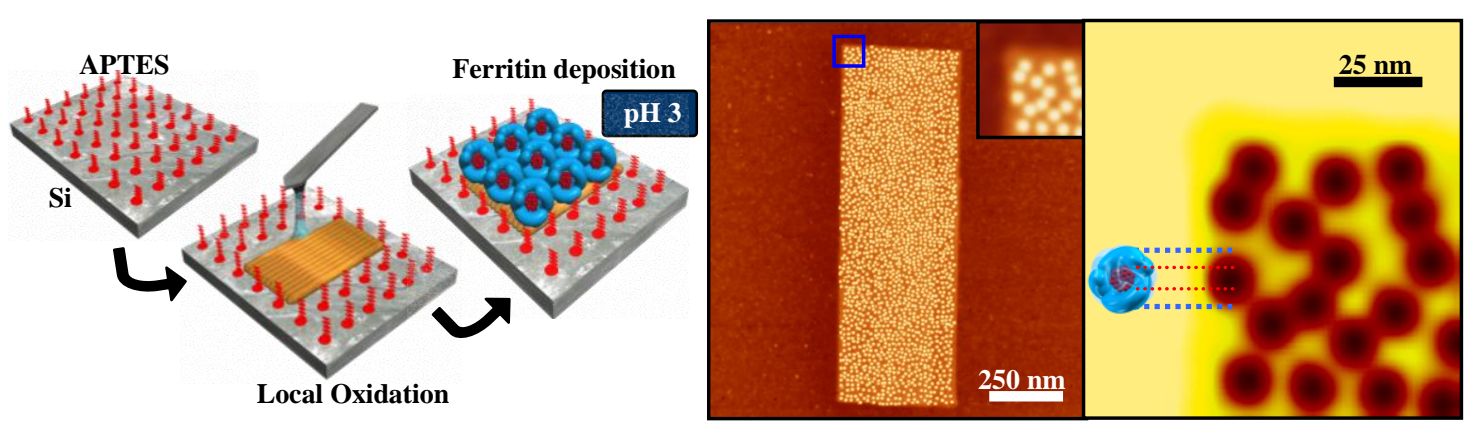

Fig. 1: Patterning of ferritin molecules by local oxidation nanolithography and silicon functionalization by APTES at low $\mathrm{pH}$ values. 


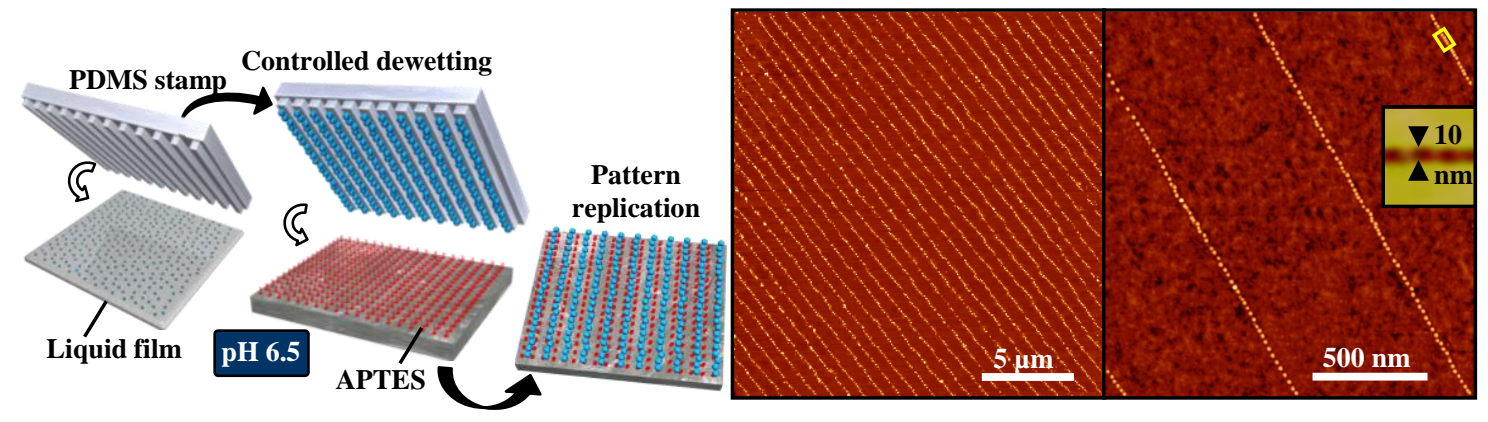

Fig. 2: Patterning of ferritin molecules over $\mathrm{cm}^{2}$ areas by controlled dewetting and surface functionalization at neutral $\mathrm{pH}$ values. 